\title{
Standards for Transition from 2D Drawing to Model Based Definition in Mechanical Engineering
}

\author{
Nomeda PUODZIUNIENE*, Evaldas NARVYDAS** \\ * Kaunas University of Technology, Studentu st. 56, LT-51424 Kaunas, Lithuania, E-mail: nomeda.puodziuniene@ktu.lt \\ ** Kaunas University of Technology, Studentu st. 56, LT-51424 Kaunas, Lithuania, E-mail: evaldas.narvydas@ktu.lt \\ crossref http://dx.doi.org/10.5755/j02.mech.25777
}

\section{Introduction}

For years, mechanical engineers have followed rigorous standards of engineering drawings. International standards (primarily ISO) have been gradually adopted in many countries allowing different people who speak different languages to read the same engineering drawing and interpret and understand it equally. Discussions on differences between two major standards for drawings: ISO and ANSI/ASME were widely presented in engineering community and reflected in textbooks for qualified draftsperson [1]. However, the contemporary Computer-Aided Design (CAD) tools together with means of Computer-Aided Manufacturing (CAM) achieved capabilities that started questioning the necessity of 2D drawings. CAD tools now create the 3D solid model at first and then 2D drawing, if needed. Solid models define a geometry of the object. Therefore, the idea to develop a 3D model that would contain all information needed for the manufacturing and more have grown to Model-based Definition (MDB) concept. Answering the needs of industry the discussion on the employment of 3D model have evolved to concept of Smart Manufacturing System [2] enabled by Model-based Enterprise and Modelbased Engineering (MBE) supported by ISO STEP (STandard for the Exchange of Product model data) AP 242 and PMI (Product Manufacturing Information) standards.

In response to the need to utilize $3 \mathrm{D} \mathrm{CAD}$ data as manufacturing and/or inspection sources, the American Society of Mechanical Engineers (ASME) issued the first version of ASME Y14.41 standard in 2003. However, in the research article of Quintana et al. (2010) [3], the conclusion based on observations within the two Canadian aerospace companies was drawn that from a cost, time and effort perspective, companies are not yet totally convinced to move to a drawing-less environment throughout the product lifecycle replacing engineering drawings with MBD datasets.

In 2013, National Institute of Standards and Technology (NIST) of the U.S. Department of Commerce issued a Model-Based Enterprise Summit Report [4]. The purpose of the Summit was to identify challenges in manufacturing, quality assurance, and system acquisition where a digital three-dimensional (3D) model serves as the authoritative information source for all activities in the product lifecycle. It concluded that the model-based methods and tools are increasing manufacturing productivity, but challenges remain introducing advanced materials such as composite structures, and advanced processes such as additive manufacturing. In addition, a new research and development are needed to address challenges such as intellectual property protection and adapting to changes in tooling, setup, or machine tool performance. The continued success of MBE requires deployment of open standards for representing and exchanging product and process data.

The improvement efforts of MBD have continued. Camba et al. [5, 6] emphasized a significance of annotation management in MBD and proposed an extended annotation manager answering questions related to CAD model design intent and reusability. Ruemler et al. (2017) [7] conducted a survey to investigate the common information model and to understand how the models are used within the companies. The result showed that the drawings are still very important source of information for a majority of the respondents. For the usability of 3D CAD models, the majority responded that information they receive and would like to receive is in native 3D CAD models; the STEP models were on the second place.

ASME Model-Based Enterprise Standards Committee Recommendation Report (2018) [8] states that today, most organizations still use engineering drawings as their authoritative source for product definition and to drive downstream operations. Currently, there is very little official documentation or standardization on MBE within industry. MBD and MBE represent a paradigm shift occurring in the way industry communicates and uses technical information today. Digital product definition (DPD) dataset is often focused upon the transition from using 2D drawings to using 3D CAD models as input to modern manufacturing. It includes the shape definition, but must also include the behavioral and contextual definitions as well.

It is very important for CAD systems to follow new modifications of released standards to ensure proper MBD. As an example, the modification of ISO 1101:2017 Geometrical product specifications (GPS) - Geometrical tolerancing - Tolerances of form, orientation, location and run-out was reviewed [9] with the call for actions implementing the standard into CAD, CMS (Coordinate Measuring Systems) data exchange, packaging and education.

MBE concept including development, manufacturing and quality control phases was implemented during a new turboprop compressor development project [10]. It gave a significant time saving, reduction of needed documentation and other benefits, although it was mentioned that creating of definition for MDB took longer comparing to traditional 2D drawing. General issues and challenges in MBD development and its full implementation in MBE, in different contexts, were identified and categorized in [11] with focus on high-value manufacturing. The overviewed of critical points on practical implementation of MBD in contemporary industry [12] show that some benefits of MBD may be overestimated and issues still exist. 


\section{Purpose of technical drawing standards}

Engineering technical drawings specify requirements of a part or assembly unit. Standards define rules for their interpretation and presentation of technical documentation. Mostly engineering drawings have information not only about the shape (geometry) of part but also about dimensions (the size of the part is fixed in accepted units) and tolerances. The orthographic projection that shows the part as it looks from the front, right, left, top, bottom, or back and is typically positioned relative to each other according to the rules of either first-angle (ISO standard and is primarily used in Europe) or third-angle projection (ANSI/ASME standard and is primarily used in the United States and Canada).

Working with CAD systems is very important selection of the right technical norms under which users will create the product and not forget the principles of technical drawings [1].

Engineering drawing has the formal and precise information about the shape, size, and precision of product. Drawing is the universal language of engineering and drawing standards are used to control the wide aspects of drawings:

- $\quad$ scales, units and quantities;

- $\quad$ lines, arrows and lettering;

- $\quad$ projections, views and sections;

- $\quad$ dimensioning and tolerance;

- $\quad$ symbols and abbreviations;

- $\quad$ surface texture indication;

- types of documentation;

- terms and definitions;

- representation of features and components

- graphical representation and annotation for 3-D modeling output;

Because we have different standards (ISO, ANSI, ...), users must not mix them up, so drawings must be created according to single family standards. Some ISO standards for technical drawing:

ISO 128-20:1996 Technical drawings - General principles of presentation - Part 20: Basic conventions for lines;

ISO 128-21:1997 Technical drawings - General principles of presentation - Part 21: Preparation of lines by CAD systems;

ISO 128-22:1999 Technical drawings - General principles of presentation - Part 22: Basic conventions and applications for leader lines and reference lines;

ISO 128-23:1999 Technical drawings - General principles of presentation - Part 23: Lines on construction drawings;

ISO 128-24:1999 Technical drawings - General principles of presentation - Part 24: Lines on mechanical engineering drawings;

ISO 128-30:2001 Technical drawings - General principles of presentation - Part 30: Basic conventions for views;

ISO 128-34:2001 Technical drawings - General principles of presentation - Part 34: Views on mechanical engineering drawings;

ISO 128-40:2001 Technical drawings - General principles of presentation - Part 40: Basic conventions for cuts and sections;

ISO 128-44:2001 Technical drawings - General principles of presentation - Part 44: Sections on mechanical engineering drawings;

ISO 128-50:2001 Technical drawings - General principles of presentation - Part 50: Basic conventions for representing areas on cuts and sections;

ISO 406:1987 Technical drawings - Tolerancing of linear and angular dimensions;

ISO 16792:2015 Technical product documentation - Digital product definition data practices;

ISO 129-1:2018 Technical product documentation (TPD) - Presentation of dimensions and tolerances - Part1: General principles;

ASME drawing standards:

ASME Y14.1- Imperial drawing sheet size and for-

mat;

ASME Y14.1M- Metric drawing sheet size and format;

ASME Y14.100- Engineering drawing and practices;

ASME Y14.2- Line conventions and lettering;

ASME Y14.3- Multi-view and sectional view drawings;

ASME Y14.5- Dimensioning and Tolerancing;

ASME Y14.24- Types and applications of Engineering drawings;

ASME Y14.34- Associated lists;

ASME Y14.35- Drawing revisions;

ASME Y14.38- Abbreviations;

ASME Y14.41- Digital product definition data practices.

\section{Digital product definition data practices}

The standard ASME Y14.41-2012 (Digital Product Definition Data Practices) defines many 3D model based product definition aspects for users [13]. The ISO 16792:2015 standard [14] standardizes MBD within the ISO standards, sharing many similarities with the ASME standard. The standard ISO 16792:2015 (Technical product documentation - Digital product definition data practices) specifies requirement for the preparation, revision and presentation of digital product definition data sets. Some companies are using it to completely define the product only with a CAD model, some might use a combination of CAD model and 2D drawing [14] Fig. 1. The information on the drawing and in the model must match. In case of using CAD model and $2 \mathrm{D}$ drawing, the standard for drawing provides the requirements.

The standard establishes rules for both model and drawing how to display information, including the full set of geometric dimensioning and tolerancing symbols. The ISO 128 series standards on general principles of presentation of technical drawings and ISO 1101:2017 - Geometrical Product Specifications (GPS) - Geometrical tolerancing - Tolerances of form orientation, location and run-out and other ISO standards dealing with surface texture, welding symbols and other technical product documentation specifications must be applied.

Product Definition Data set Fig. 2 completely defines a product by this aspect: geometry, annotation, attribute data, reference to standards, specification. The model itself includes geometric elements in product definition data representing the designed product. Annotations include dimensions, tolerances, notes, text, or symbols. 


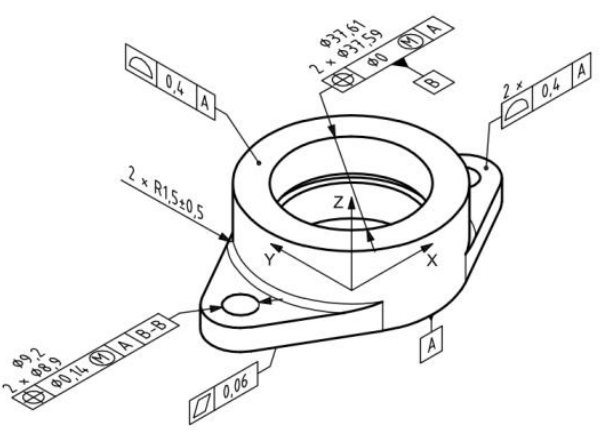

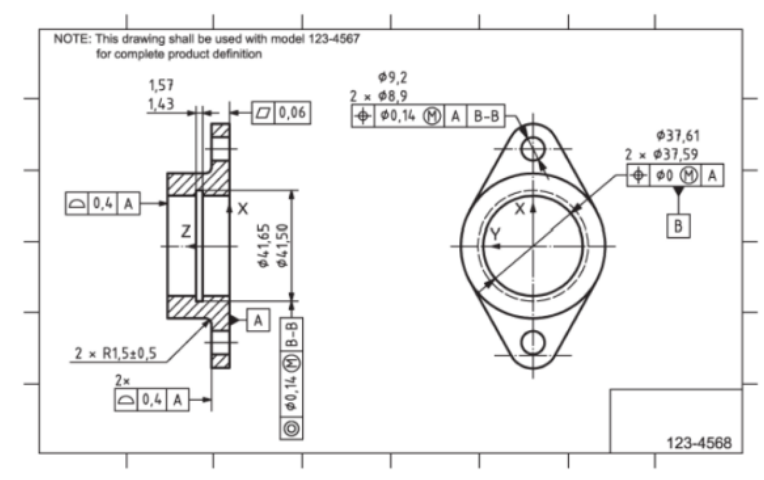

b

Fig. 1 Design model and drawing [14]: a - annotated model, b - drawing

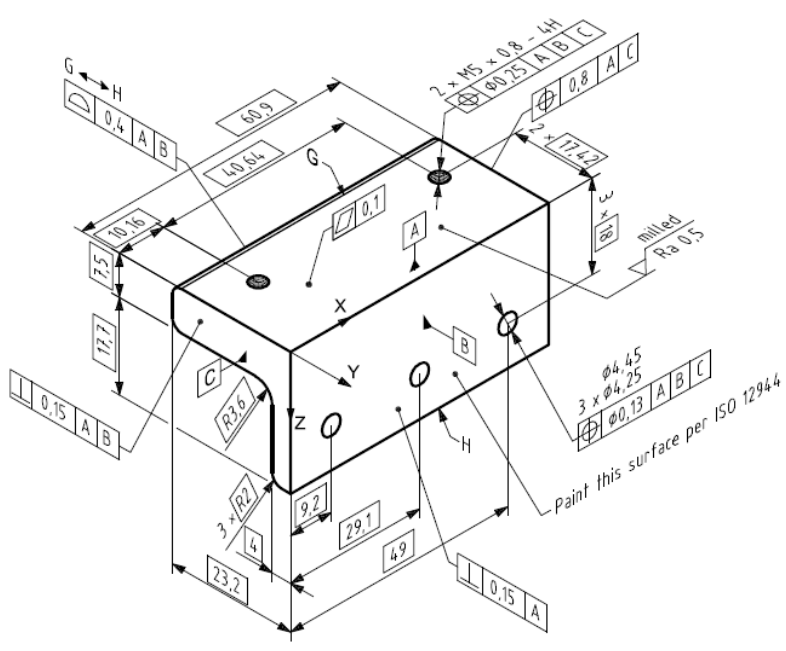

a

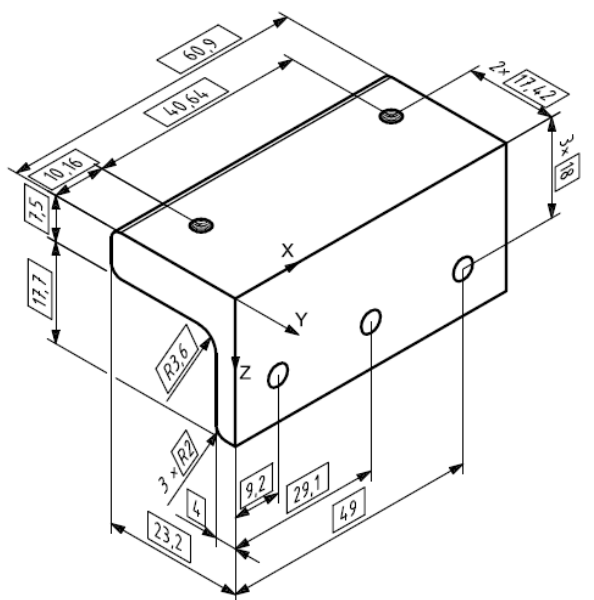

b

Fig. 2 Model with different annotation [14]: a) model with all annotation, b) model with one type annotation

Attributes are such elements as a dimension, tolerance, note, text, or symbol required to complete the product definition [14].

A model coordinate system shall be included in each axonometric view to indicate orientation of the view, and section views can be created also from axonometric views Fig. 3. A representation of a cutting plane shall be used to indicate the location and viewing direction of a section. The cutting plane and the cuts and sections shall be indicated according to ISO 128-40 and ISO 128-44 standards.

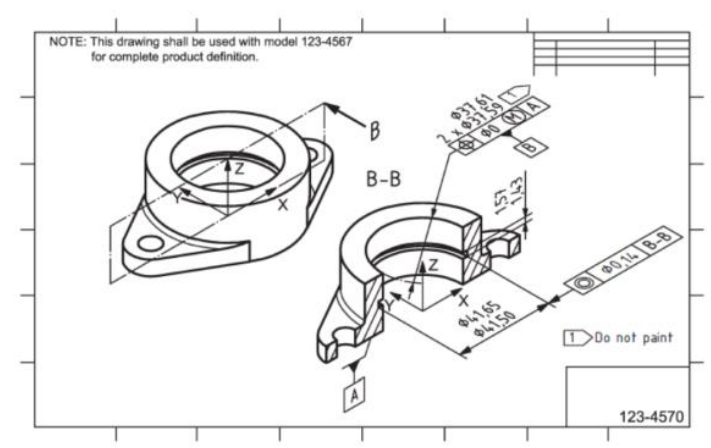

Fig. 3 Axonometric view views [14]

The result of the section cut may be shown either by removing material from the part Fig. 3 or by display of the curves overlaid on the view that result from intersecting the cutting plane with the part Fig. 4 [14].

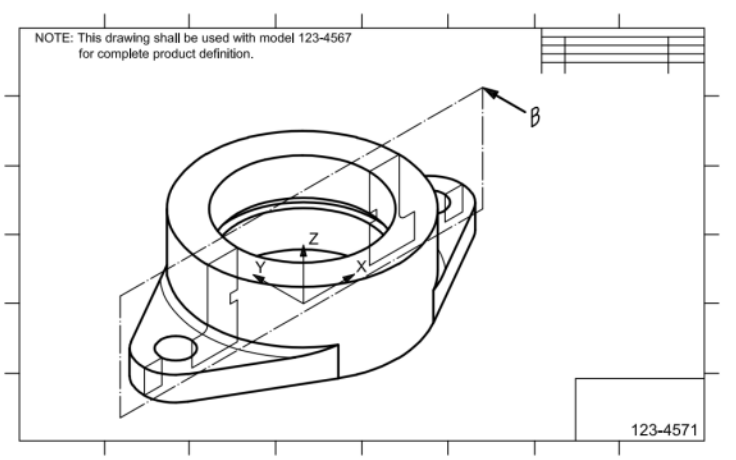

Fig 4 Section curves shown in an axonometric view [14]

According standard ISO 16792:2015 the users have possibility to indicate dimensions and annotations on the 3D model that allows thinking in three dimensions. This standard covers the historical practices of using engineering drawings to define a product and the practices, requirements, and interpretation of the CAD data when there is no engineering drawing.

\section{Conclusions}

CAD systems enable designers to view objects under a wide variety of representations. However, as in the manual drafting of technical and engineering drawings, the 
output of CAD must have information, such as product geometry, process, dimensions and tolerances, according to basic valid standards in order to avoid elementary mistakes of technical drawings.

According standard ISO 16792:2015 the users have possibility to indicate dimensions and annotations on the 3D model that allows thinking in three dimensions. This standard cover the historical practices of using engineering drawings to define a product and the practices, requirements, and interpretation of the CAD data when there is no engineering drawing.

The MBD practice is still under the development. Large effort is applied from standardization institutions, researchers and engineers to over the issues and challenges the MBD is facing. This will results in significant savings and a new level of product lifecycle management.

\section{References}

1. Simmons, C.H.; Maguire, D. E. Phelps, N. 2012. The Manual of Engineering Drawing: Technical Product Specification and Documentation to British and International Standards. 4th Edition. - Oxford: Elsevier/Butterworth Heineman $384 \mathrm{p}$.

2. Feeney, A. B.; Frechette, S. P.; Srinivasan, V. 2015. A Portrait of an ISO STEP tolerancing standard as an enabler of smart manufacturing systems, Journal of Computing and Information Science in Engineering 15(2): 1-5.

https://doi.org/10.1115/1.4029050.

3. Quintana, V.; Rivest, L.,; Pellerin, R. ; Venne, F. ; Kheddouci, F. 2010. Will model-based definition replace engineering drawings throughout the product lifecycle? A global perspective from aerospace industry, Computers in Industry 61: 497-508. https://doi.org/10.1016/j.compind.2010.01.005.

4. Lubell, J.; Frechette, S.bP.; Lipman, R.bR.; Proctor, F.bM.; Horst, J.bA.; Carlisle, M.; Huang, P.bJ. 2013. Model-Based Enterprise Summit Report, NIST Technical Note 1820, U.S. Department of Commerce. http://dx.doi.org/10.6028/NIST.TN.1820.

5. Camba, J.; Contero, M.; Johnson, M.; Company, P. 2014. Extended 3D annotations as a new mechanism to explicitly communicate geometric design intent and increase CAD model reusability, Computer-Aided Design 57: 61-73. https://doi.org/10.1016/j.cad.2014.07.001.

6. Camba, J. D.; Contero, M. 2015. Assessing the Impact of Geometric Design Intent Annotations on Parametric Model Alteration Activities, Computers in Industry 71: $35-45$. http://dx.doi.org/10.1016/j.compind.2015.03.006.

7. Ruemler, S. P.; Zimmerman, K. E; Hartman, N. W.; Hedberg, T. Jr.; Feeny, A. B. 2017. Promoting modelbased definition to establish a complete product definition, Journal of Manufacturing Science and Engineering-Transactions of the ASME 139 (5): 1-7. https://doi.org/10.1115/1.4034625.
8. ASME, Model-Based Enterprise Steering Group. 2018. Model-Based Enterprise Standards, Committee Recommendation Report. 43 p.

9. Morse, E. P; Shakarji, C. M.; Srinivasan V. A brief analysis of recent ISO tolerancing standards and their potential impact on digitization of manufacturing, 15th CIRP Conference on Computer Aided Tolerancing CIRP CAT 2018, Procedia CIRP 75: 11-18. https://doi.org/10.1016/j.procir.2018.04.080.

10. Paruszewski, P.; Lis, P.; Lipiński, L. 2019. Model based enterprise (MBE) in prototype compressor project for new turboprop engine, AIP Conference, Proceedings 2078: 020042-1-020042-6. https://doi.org/10.1063/1.5092045.

11. Goher, K.; Shehab, E.; Al-Ashaab A. 2019. Challenges of model-based definition for high-value manufacturing, In: Jin Y., Price M. (Eds.) Advances in Manufacturing Technology XXXIII- Proceedings of the 17th International Conference on Manufacturing Research, incorporating the 34th National Conference on Manufacturing Research, 10-12 September 2019, Queen's University, Belfast: IOS Press: 22-27. https://doi.org/10.3233/ATDE190006,

12. Bijnens, J; Cheshire, D. 2019. The Current state of model based definition, Computer-Aided Design and Applications16(2): 308-317, https://doi.org/10.14733/cadaps.2019.308-317.

13. ASME, Digital Product Definition Data Practices (ASME Y14.41-2012). 2012. The American Society of Mechanical Engineers.

14. ISO. 2015. Technical product documentation - Digital product definition data practices (ISO 16792: 2015). International Organization for Standards.

N. Puodziuniene, E. Narvydas

\section{STANDARDS FOR TRANSITION FROM 2D DRAWING TO MODEL BASED DEFINITION IN MECHANICAL ENGINEERING}

S u m m a r y

The main tools of CAD: the simple 2D Drawing/Drafting or 3D Parametric Feature Based Solid/Surface Modelling are used for product development. CAD systems increase the quality of drawings and reduce the time for its preparation. In this process, it is very important to use the valid standards in the drawings and technical documentation. Standardization documents describing the rules, regulations and requirements of production methods, concepts, symbols, constructor's drawings and documents are very important in all areas of industry.

Keywords: automated design systems, CAD/CADD, model based product definition, standardization of technical documentation.
Received April 13, 2020

Accepted August 07, 2021 